previously treated with fluconazole. A randomized trial comparing the efficacy of voriconazole with that of echinocandins for the treatment of candidemia is warranted.

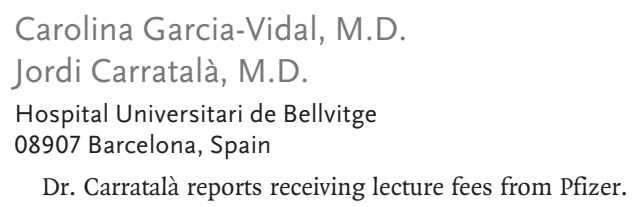

1. Bennett JE. Echinocandins for candidemia in adults without neutropenia. N Engl J Med 2006;355:1154-9.

2. Kullberg BJ, Sobel JD, Ruhnke M, et al. Voriconazole versus a regimen of amphotericin B followed by fluconazole for candidaemia in non-neutropenic patients: a randomised non-inferiority trial. Lancet 2005;366:1435-42.

3. Ostrosky-Zeichner L, Rex JH, Pappas PG, et al. Antifungal susceptibility survey of 2000 bloodstream Candida isolates in the United States. Antimicrob Agents Chemother 2003;47:3149-54. 4. Panackal AA, Gribskov JL, Staab JF, et al. Clinical significance of azole antifungal drug cross-resistance in Candida glabrata. J Clin Microbiol 2006;44:1740-3.

THE AUTHOR REPLIES: The recently published Swiss guidelines concur with the view of GarciaVidal and Carratalà that voriconazole should be considered as one of the second-line agents for treatment of candidemia in nonneutropenic pa- tients with no prior exposure to an azole. ${ }^{1}$ However, I see no clear indication for selecting voriconazole over fluconazole for such patients. Candida species with reduced susceptibility to fluconazole have proportionally reduced susceptibility to voriconazole. The major indication for the use of voriconazole is its clinical efficacy against invasive mold infections. ${ }^{2}$ For candidemia, fluconazole is the preferred azole because of its superior safety profile, fewer known drug interactions, and lower cost, and because of the absence of restrictions on intravenous administration in patients with a creatinine clearance below $50 \mathrm{ml}$ per minute. ${ }^{3}$

John E. Bennett, M.D.

National Institute of Allergy and Infectious Diseases Bethesda, MD 20892

1. Flückiger U, Marchetti O, Bille J, et al. Treatment options of invasive fungal infections in adults. Swiss Med Wkly 2006;136: 447-63.

2. Herbrecht R, Denning DW, Patterson TF, et al. Voriconazole versus amphotericin B for primary therapy of invasive aspergillosis. N Engl J Med 2002;347:408-15.

3. Kofla G, Ruhnke M. Voriconazole: review of a broad spectrum triazole antifungal agent. Expert Opin Pharmacother 2005;6: 1215-29.

\title{
Effects of Dietary Nitrate on Blood Pressure in Healthy Volunteers
}

TO THE EDITOR: Nitric oxide, generated by nitric oxide synthase, is a key regulator of vascular integrity. This system is dysfunctional in many cardiovascular disorders, including hypertension. A fundamentally different pathway for the generation of nitric oxide was recently described in which the anions nitrate $\left(\mathrm{NO}_{3}^{-}\right)$and nitrite $\left(\mathrm{NO}_{2}^{-}\right)$are converted into nitric oxide and other bioactive nitrogen oxides. ${ }^{1-3}$ Nitrate is abundant in our diet, and particularly high levels are found in many vegetables. $^{3}$

We examined the effect of 3-day dietary supplementation with either sodium nitrate (at a dose of $0.1 \mathrm{mmol}$ per kilogram of body weight per day) or placebo (sodium chloride, at a dose of $0.1 \mathrm{mmol}$ per kilogram per day) on blood pressure in 17 physically active, healthy volunteers, none of whom smoked (15 men and 2 women; mean age, 24 years). The study had a randomized, doubleblind, crossover design with two different treatment periods during which the subjects received either nitrate or placebo; the treatment periods were separated by a washout period of at least 10 days. The compounds were dissolved in water and could not be distinguished by taste or appearance. During the two treatment periods, the subjects were instructed to avoid all foods with a moderate or high nitrate content. ${ }^{3}$

Systolic blood pressure (Fig. 1A) and pulse rate did not change significantly after nitrate supplementation, as compared with placebo supplementation. However, the diastolic blood pressure was on average $3.7 \mathrm{~mm} \mathrm{Hg}$ lower after nitrate supplementation than after placebo supplementation $(\mathrm{P}<0.02)$ (Fig. 1B), and the mean arterial pressure was $3.2 \mathrm{~mm} \mathrm{Hg}$ lower $(\mathrm{P}<0.03)$. Plasma nitrate levels were higher after nitrate ingestion than after placebo ingestion (mean $[ \pm S D], 178 \pm 51$ and $26 \pm 11 \mu \mathrm{M}$, respectively; $\mathrm{P}<0.001$ ), as were plasma nitrite levels (219 \pm 105 and $138 \pm 38 \mathrm{nM}$, respectively; $\mathrm{P}<0.01$ ).

The daily nitrate dose used in the study corresponds to the amount normally found in 150 to $250 \mathrm{~g}$ of a nitrate-rich vegetable such as spinach, beetroot, or lettuce. It is clear from earlier studies, such as the Dietary Approaches to Stop Hyperten- 


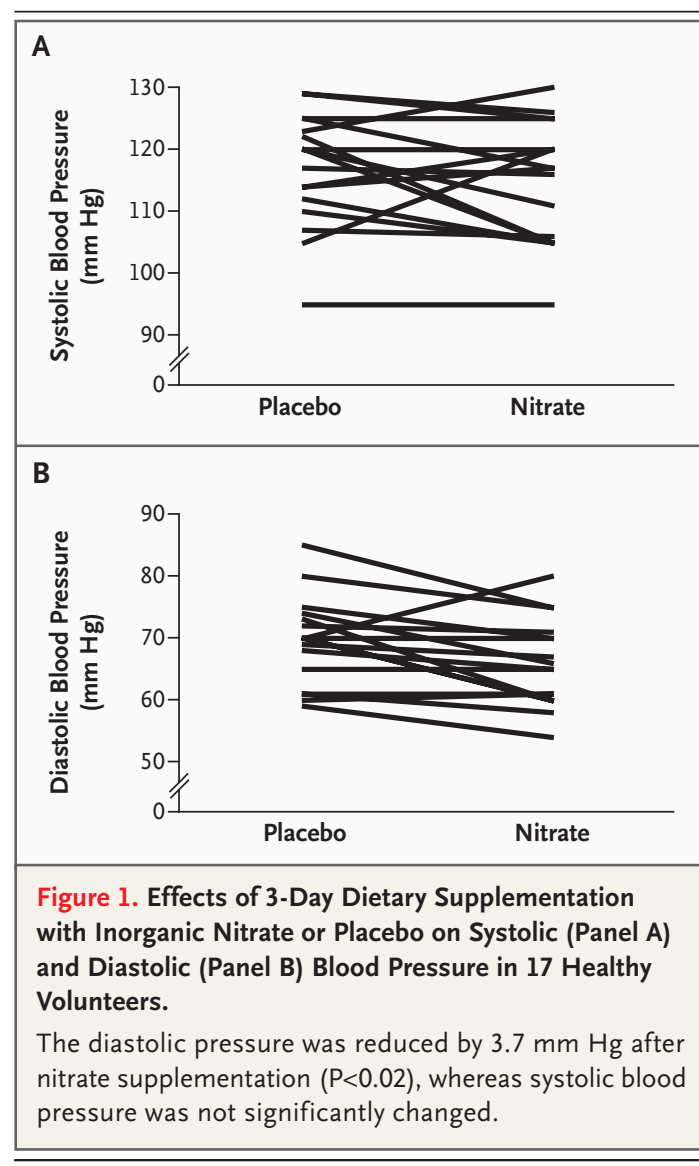

sion (DASH) trial, that a diet rich in fruits and vegetables can reduce blood pressure, ${ }^{4,5}$ but attempts to modify single nutrients have been inconsistent. Therefore, it has been argued that the effect of any individual nutrient is too small to detect in trials. In our study, reduced blood pres- sure was associated with nitrate supplementation alone; this effect was evident in young normotensive subjects. In fact, it was similar to that seen in the healthy control group in the DASH study. ${ }^{4}$ The exact mechanism behind the blood-pressurelowering effect of nitrate needs to be clarified in future studies.

We conclude that short-term dietary supplementation with inorganic nitrate reduces diastolic blood pressure in healthy young volunteers.

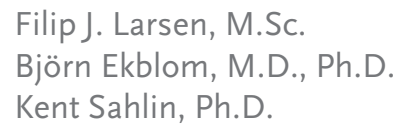

Supported by grants from the Swedish Research Council, the Swedish Heart and Lung Foundation, and the European Community's Sixth Framework Program (Eicosanox, LSMH-CT-2004005033).

1. Lundberg JO, Weitzberg E. NO generation from nitrite and its role in vascular control. Arterioscler Thromb Vasc Biol 2005; 25:915-22.

2. Gladwin MT, Schechter AN, Kim-Shapiro DB, et al. The emerging biology of the nitrite anion. Nat Chem Biol 2005;1:308-14. [Erratum, Nat Chem Biol 2006;2:110.]

3. Lundberg JO, Weitzberg E, Cole JA, Benjamin N. Nitrate, bacteria and human health. Nat Rev Microbiol 2004;2:593-602.

[Erratum, Nat Rev Microbiol 2004;2:681.]

4. Appel LJ, Moore TJ, Obarzanek E, et al. A clinical trial of the effects of dietary patterns on blood pressure. N Engl J Med 1997; 336:1117-24.

5. Rouse IL, Beilin LJ, Armstrong BK, Vandongen R. Bloodpressure-lowering effect of a vegetarian diet: controlled trial in normotensive subjects. Lancet 1983;1:5-10.

Correspondence Copyright $\odot 2006$ Massachusetts Medical Society.

INSTRUCTIONS FOR LETTERS TO THE EDITOR

Letters to the Editor are considered for publication, subject to editing and abridgment, provided they do not contain material that has been submitted or published elsewhere. Please note the following: $\cdot$ Letters in reference to a Journal article must not exceed 175 words (excluding references) and must be received within three weeks after publication of the article. Letters not related to a Journal article must not exceed 400 words. All letters must be submitted over the Internet at http://authors.nejm.org. -A letter can have no more than five references and one figure or table. •A letter can be signed by no more than three authors. - Financial associations or other possible conflicts of interest must be disclosed. (Such disclosures will be published with the letters. For authors of Journal articles who are responding to letters, this information appears in the original articles.) •Include your full mailing address, telephone number, fax number, and e-mail address with your letter.

Our Web site: http://authors.nejm.org

We cannot acknowledge receipt of your letter, but we will notify you when we have made a decision about publication. Letters that do not adhere to these instructions will not be considered. Rejected letters and figures will not be returned. We are unable to provide prepublication proofs. Submission of a letter constitutes permission for the Massachusetts Medical Society, its licensees, and its assignees to use it in the Journal's various print and electronic publications and in collections, revisions, and any other form or medium. 